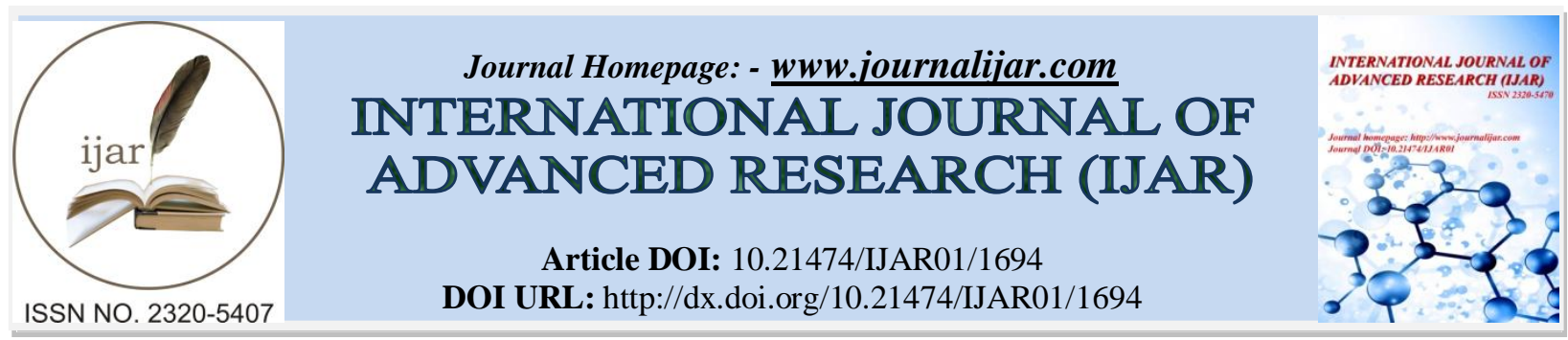

RESEARCH ARTICLE

\title{
COMPARISON OF SERVOMOTOR PERFORMANCE WITH PI AND PID CONTROLLER USED IN TEXTILE PRINTING MACHINE
}

Thwin Thu Lynn

Department of Electrical Power Engineering, Yangon Technological University, Union of Myanmar.

\section{Manuscript Info}

Manuscript History

Received: 21 July 2016

Final Accepted: 25 August 2016

Published: September 2016

Key words:-

BLDC servomotor, nonlinear, PI and

PID controller, Matlab

\section{Abstract}

This paper presents the application of servomotor used in textile printing machine. For the control system, PI (proportional-integral) and PID (proportional-integral-derivative) controllers are proposed. System performance is analyzed by comparing the two applications of PI and PID controllers. Simulation is carried by using Matlab/simulink to demonstrate the performance of the proposed PI and PID controllers in servo motor drive.

Copy Right, IJAR, 2016,. All rights reserved.

\section{Introduction:-}

The electric drive system is a vital part to drive any motor. The electric drive system is used to control the position, speed and torque of the electric motors. Many works has been done on power converter topologies, control scheme of the electric drive systems and on the motor types in order to enhance and improve the performance of the electric motors so as to exactly perform and do what is required [1].

Brushless DC servomotors have some advantages over conventional brushed motors and induction motors. Some of these are; better speed versus torque characteristics, high dynamic response, high efficiency, long operating life, noiseless operation and higher speed ranges. In addition Brushless DC (BLDC) servomotors are reliable, easy to control, and inexpensive. Due to their favorable electrical and mechanical properties, BLDC servomotors are widely used in servo applications such as automotive, aerospace, medical, instrumentation, actuation, robotics, machine tools, and industrial automation equipment and so on recently [2].

Classical PI and PID controllers are commonly used in industries due to their simplicity and ease of implementation [3]. In linear system model, controller parameters of the proposed controller are easy to determine and resulting good control performances. However, for nonlinear system model applications such as BLDC servomotor drive, control performance of the proposed controller becomes poor and difficult to determine the controller parameters [4].

In this research, the operating processes of the Flat-Bed Screen Printing machine at Yamathin textile factory that is located in Mandalay division are considered. After that, a complete simulation model of the application of the operation of a servomotor using PI and PID controller drive is proposed using Matlab/Simulink. By applying it, it can be reduced the occurring of disturbances and uncertainties more than the other classical methods. The proposed controllers which own controller parameters are based on external disturbance and internal variation of the converter with minimum steady state error, overshoot and rise time of the output voltage.

Corresponding Author:- Thwin Thu Lynn.

Address:- Department of Electrical Power Engineering, Yangon Technological University Myanmar. 


\section{Operational process of textile printing machine:-}

Fig. 1 shows the process of the textile printing machine, it is mainly included three parts. These are the fabric carriage, making boundaries and filling ink, washing and drying machine. Firstly, fabric carriage was drawn one meter of the non-color fabric raw material. Secondly, it was passed through the printing processes area which makes boundaries and filling ink by driving the strokes. After that, the processing of washing and drying on the clothing is done. This is also called the finishing part of the overall of the printing machine.

In the textile printing machine, two servomotors are used to synchronize the balancing on the printing process area. The one is fixed on the starting and the other is fixed on the ending of process because of system synchronizing. It includes the encoder to get the exact positioning. The control signal is sent to the encoder by passing the motion control. Moreover, the positioning signal is again sent to the controller driver which is accessed from the servo amplifier. Finally, it will reach the host computer to set all of motion signals.

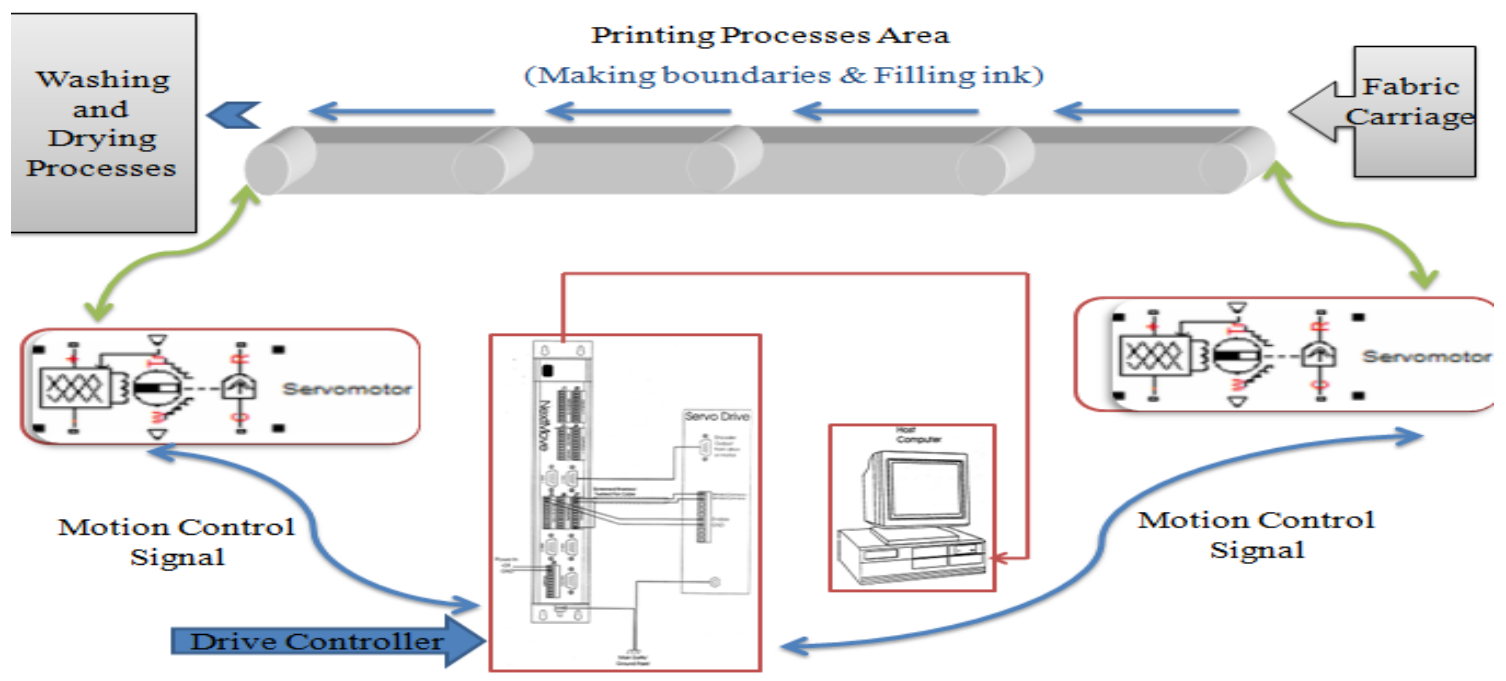

Fig.1:- Overall diagram of processing of Textile Printing Machine.

Electrical motor torque is proportional to the product of magnetic flux and the armature current. Mechanical or load torque is proportional to the product of force and distance. Motor current varies in relation to the amount of load torque applied. When a motor is running in steady state, the armature current is constant, and the electrical torque is equal and opposite of the mechanical torque. When a motor is decelerating, the motor torque is less than the load torque. Inversely, in the accelerating process, the motor torque is higher than the load torque [5].

\section{Components of the servo control:-}

In this brushless DC servomotor, the following devices would be used such as incremental encoder to get the pulse per revolution that concluding the positioning control.

\section{Incremental Encoder:-}

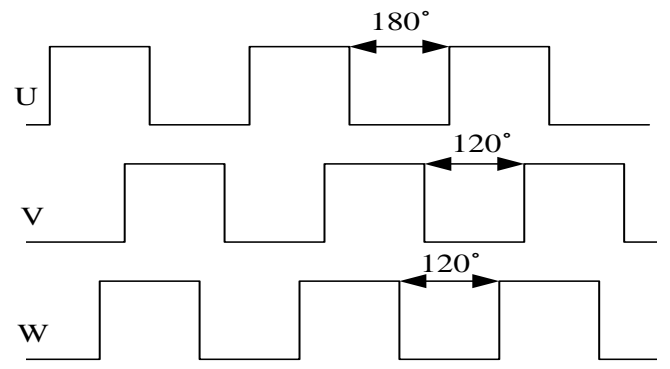

Fig 2:- Pulses of encoder [6]. 


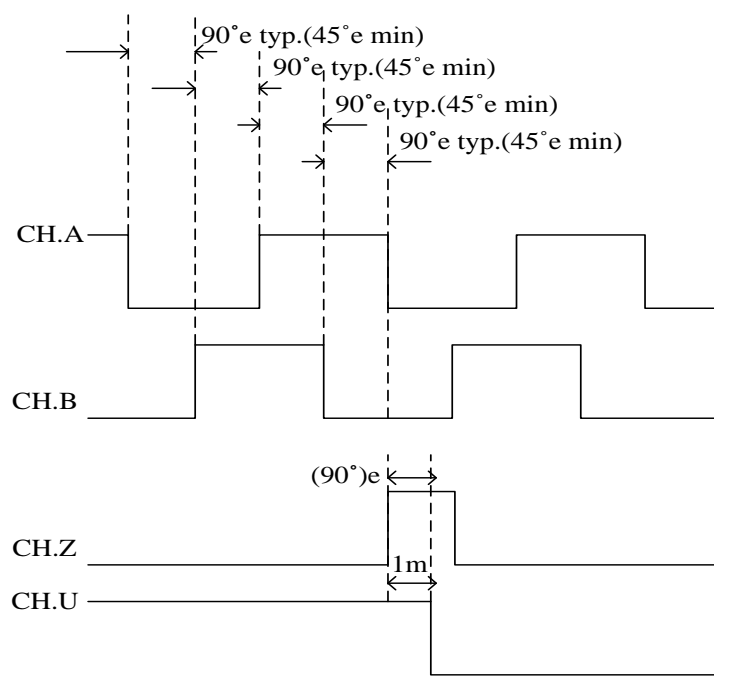

Fig. 3:- Incremental encoder [6]

Fig. 3 shows the incremental encoders having two separate outputs called "Quadrature outputs". These two outputs are displaced at 90 degrees out of phase from each other with the direction of rotation of the shaft being determined from the output sequence [6].

\section{Velocity from Position Encoder:-}

Linear servomotors are mostly used in applications of high acceleration and deceleration, high velocity or precise velocity control at low speed [7].

Speed and velocity are kinematic quantities that have different definitions. Speed is the rate at which an object covers distance. The average speed is the distance per time ratio. Speed is ignorant of direction.

On the other hand, velocity is a vector quantity; it is direction-aware. Velocity is the rate at which the position changes. The average velocity is the displacement or position change per time ratio. The instantaneous speed of an object is not confused with the average speed. The definition of the average speed is equal to the displacement divided by time travelled [6].

\section{Control methods:-}

\section{Servomotor's Characteristics:-}

In the analysis of electric servo drive motors, the equations for the motor indicate the presence of two time constants. One is a mechanical time constant and the other is an electrical time constant. Since these two time constants are part of the motor block diagram used in a servo analysis, it is important to know the real value of the time constants under actual load conditions [8].

A derivation of the motor equations and the electrical and mechanical motor time constants will be discussed for the dc brushless servo motor. Fig.4 shows the de servo motor equivalent diagram [8].

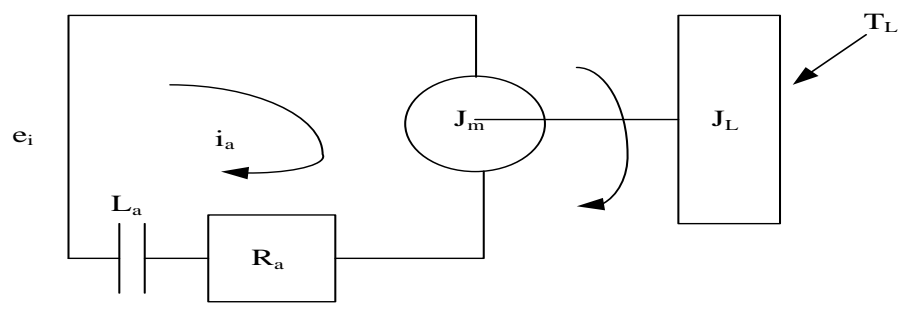

Fig.4:- DC servo motor equivalent diagram [8] 


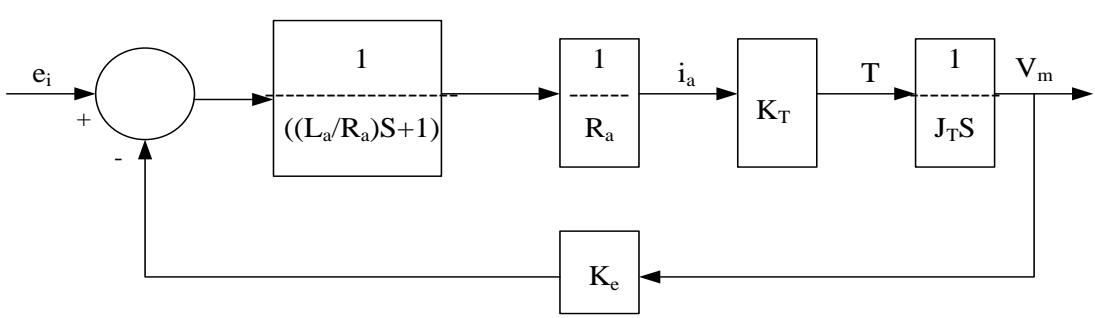

Fig.5:- Model of transfer function [8]

where: $\mathrm{e}_{1}=$ Applied voltage (volts)

$\mathrm{i}_{\mathrm{a}} \quad=$ Armature current (amps)

$\mathrm{J}_{\mathrm{T}} \quad=$ Total inertia of motor armature plus load (lb-in-sec ${ }^{2}$ )

$\mathrm{K}_{\mathrm{e}}=$ Motor voltage constant $(\mathrm{v} / \mathrm{rad} / \mathrm{sec})$

$\mathrm{K}_{\mathrm{T}}=$ Motor torque constant (lb-in/A)

$\mathrm{L}_{\mathrm{a}} \quad=$ Motor winding inductance (Henries)

$\mathrm{R}_{\mathrm{a}}=$ Armature resistance (ohms)

$\mathrm{V}_{\mathrm{m}}=$ Motor velocity $(\mathrm{rad} / \mathrm{sec})$

$\alpha \quad=$ Acceleration $\left(\mathrm{rad} / \mathrm{sec}^{2}\right)$

From Fig.5, the steady state equations are:

$\mathrm{e}_{\mathrm{i}}=\mathrm{i}_{\mathrm{a}} \mathrm{R}_{\mathrm{a}}+\mathrm{K}_{\mathrm{e}} \mathrm{V}_{\mathrm{m}}$

$\mathrm{T}=\mathrm{i}_{\mathrm{a}} \mathrm{K}_{\mathrm{T}}=\mathrm{J} \alpha$

The transfer function is:

$$
\frac{\mathrm{V}_{\mathrm{m}}}{\mathrm{e}_{\mathrm{i}}}=\frac{\frac{1}{\mathrm{~K}_{\mathrm{e}}}}{\left(\frac{\mathrm{R}_{\mathrm{a}} \mathrm{J}_{\mathrm{T}}}{\mathrm{K}_{\mathrm{e}} \mathrm{K}_{\mathrm{T}}}\right)\left(\frac{\mathrm{L}_{\mathrm{a}}}{\mathrm{R}_{\mathrm{a}}}\right) \mathrm{S}^{2}+\left(\frac{\mathrm{R}_{\mathrm{J}} \mathrm{J}_{\mathrm{T}}}{\mathrm{K}_{\mathrm{e}} \mathrm{K}_{\mathrm{T}}}\right) \mathrm{S}+1}
$$

Cascade Control Structure:-

The cascade control structure used for its flexibility of providing relatively separate control for different condition.

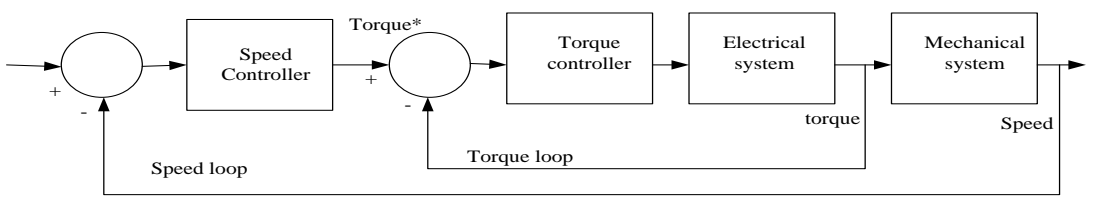

Fig.6:- Cascade control structure [9]

Fig.6 shows a cascade control system for DC motor drive. It provides control for torque (current) and speed. Precise control for speed and torque is implemented. There are two control loops in the system which are speed loop and torque loop. In each loop, PI and PID controller are designed [9]. The respective parameters of servomotor are shown in Table $\mathbf{i}$ and Table ii.

Table i:- Parameters of electrical torque.

\begin{tabular}{|l|l|}
\hline \multicolumn{1}{|c|}{ Parameters } & \multicolumn{1}{c|}{ Ratings } \\
\hline Rotational speed & $3000 \mathrm{rpm}$ \\
\hline Maximum torque & $34 \mathrm{Nm}$ \\
\hline Torque control time constant & $0.5 \mathrm{e}^{-3}$ \\
\hline Motor and drives overall efficiency (\%) & 50 \\
\hline Speed at efficiency & $1200 \mathrm{rpm}$ \\
\hline Torque at efficiency & $200 \mathrm{Nm}$ \\
\hline Torque independent electrical losses & $300^{*} 44 \mathrm{e}^{-3} \mathrm{Nm}$ \\
\hline Supply series resistance & $2 \mathrm{ohm}$ \\
\hline
\end{tabular}


Table ii:- parameters of mechanical torque.

\begin{tabular}{|l|l|}
\hline \multicolumn{1}{|c|}{ Parameters } & \multicolumn{1}{c|}{ Ratings } \\
\hline Rotor inertia & $0.3082 \mathrm{kgm}^{2}$ \\
\hline Rotor damping & 0.1 \\
\hline Initial rotor speed & 0 \\
\hline Reference voltage & $24 \mathrm{~V}$ \\
\hline Rated voltage & $300 \mathrm{~V}$ \\
\hline Integral gain & 0.04 \\
\hline Proportional gain & 0.001 \\
\hline Derivative gain & 0.0004 \\
\hline
\end{tabular}

\section{PI Controller:-}

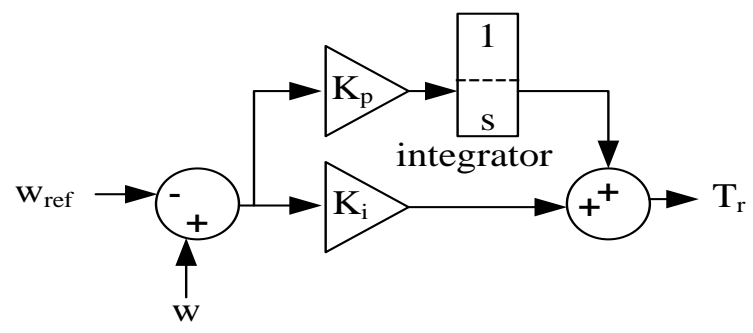

Fig.7:- controller of servo motor.

where $\mathrm{w}=$ output speed, $\mathrm{w}_{\mathrm{ref}}=$ reference output speed, $\mathrm{K}_{\mathrm{p}}=$ proportional gain, $\mathrm{K}_{\mathrm{i}}=$ integral gain, $\mathrm{T}_{\mathrm{r}}=$ integral time . A proportional-integral (PI) filter algorithm and velocity and acceleration feed-forward enhance servo control of the axis. In addition, the programming of acceleration and deceleration profiles controls that goes with starting and stopping motion. This gives smoother, more than other controlled operation, leading to quicker settling times for both position and velocity.

Torque $\mathrm{T}_{\mathrm{r}}=\left(\mathrm{K}_{\mathrm{p}} / \mathrm{s}\right)+\mathrm{K}_{\mathrm{i}}$

If the controller is digital, then the derivative term may be replaced with a backward difference and the integral term replaced with a sum. For a small constant sampling time can be approximated [9].

\section{PID Controller:-}

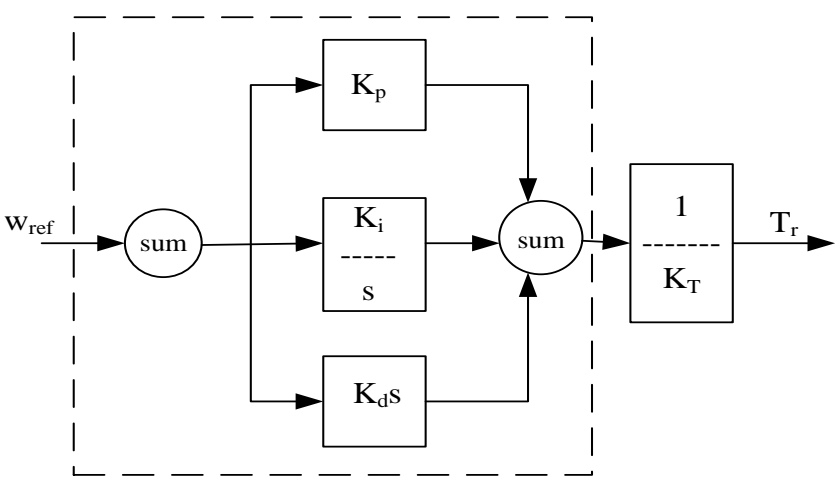

Fig.8:- PID controller of servo motor.

PID stands for "proportional, integral, derivative." These three terms describe the basic elements of a PID controller. Each of these elements performs a different task and has a different effect on the functioning of a system.

The Ziegler-Nichols Step Response Method:

$\mathrm{C}(\mathrm{s})=\mathrm{k}_{\mathrm{p}}+\mathrm{k}_{\mathrm{i}} / \mathrm{s}+\mathrm{k}_{\mathrm{d}} \mathrm{s}$ 
This method is an experimental close-loop tuning method and is applicable to close-loop stable plants.

\section{Simulation Results:-}

For system design, it is not usually necessary to model the current switching controlled by the motor driver whereas ensuring the correct torque-speed characteristics and current drawn from the DC supply. Fig.9 shows simulation model of brushless de servo motor with PI controller and Fig. 11 shows the simulation model of brushless de servo motor with PID controller.

In this system, the standard configuration is modeled an inner feedback loop controls current and an outer feedback loop controls motor speed. Speed demand is set by the voltage presented $\mathrm{V}_{\text {ref }}(24 \mathrm{~V}), 3000 \mathrm{rpm}$. Motor direction is controlled by the voltage presented at the $\mathrm{V}_{\mathrm{dir}}$ which is set step-change at one second. Braking is controlled by the voltage which is set a step-chance after two seconds.

Table iii:- parameters of brushless dc servomotor.

\begin{tabular}{|l|l|}
\hline Parameters & Ratings \\
\hline Nominal voltage & $300 \mathrm{~V}$ \\
\hline No-load DC current to driver & $44 \mathrm{e}^{-3} \mathrm{~A}$ \\
\hline Current loop time constant & $0.5 \mathrm{e}^{-3}$ \\
\hline Efficiency & $50 \%$ \\
\hline Speed & $1200 \mathrm{rpm}$ \\
\hline Rated Torque & $27 \mathrm{Nm}$ \\
\hline Stall torque & $34 \mathrm{Nm}$ \\
\hline Rotor inertia & $0.3082 \mathrm{kgm}^{2}$ \\
\hline Proportional gain & 0.001 \\
\hline Integral gain & 0.04 \\
\hline Derivative gain & 0.0004 \\
\hline Maximum reference voltage & $24 \mathrm{~V}$ \\
\hline
\end{tabular}

The parameters shown in Table iii represent a servomotor and driver operating torque-control mode. Regarding the data based on the assumption, the torque is proportional to the current which is equivalent to the driver controlling current. The motor's permissible range of torque and speed is defined by the manufacturer torque-speed envelope, and the output torque is assumed to track the torque reference demand with time constant. Electrical losses assume to be the sum of a torque-independent term plus a term proportional to the square of the torque. In addition, a resistor in series with the supply represents to model transmission losses between power supply and servomotor driver.

At the simulation results of no load condition, motor speed reaches maximum $3000 \mathrm{rpm}$. The braking time reaches at $25 \mathrm{~s}$. Therefore, electrical power in kilowatts produces $10.5 \mathrm{~kW}$ as motor output. The peak current reaches $38 \mathrm{~A}$ at the same time. By means of no load condition, mechanical power has no output.

\section{Case 1: PI condition}

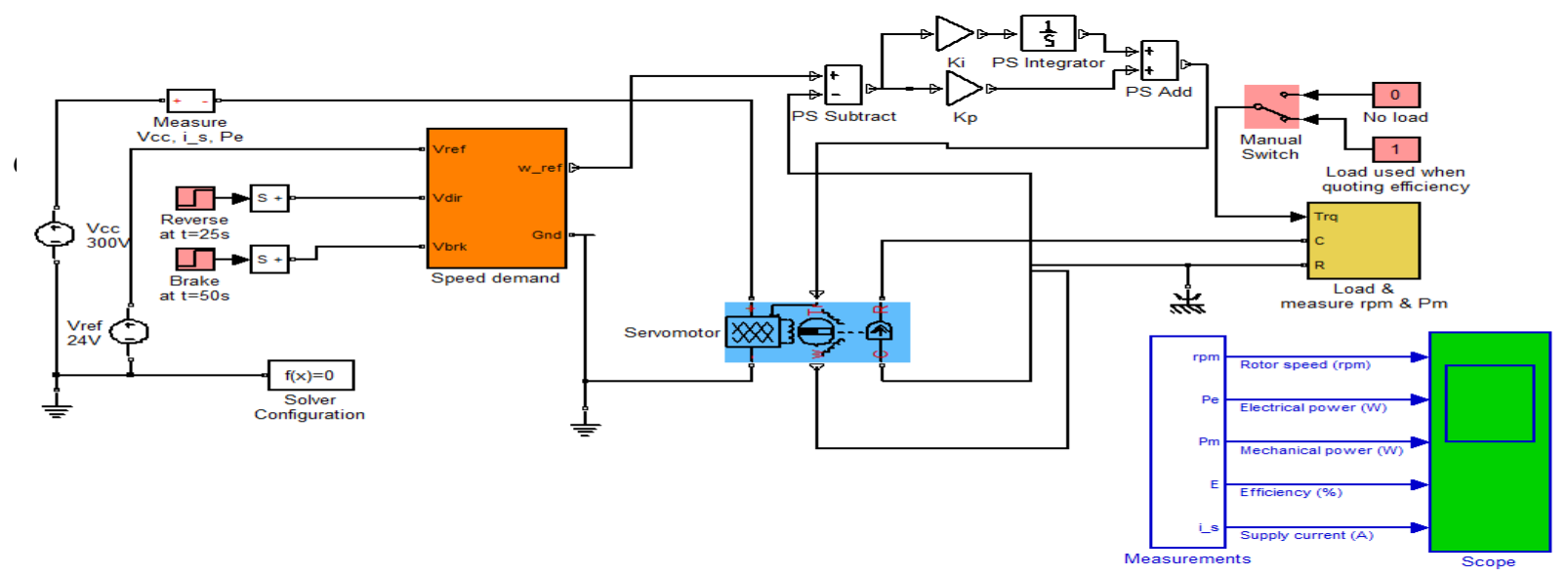

Fig.9:- Simulation model of brushless dc servo motor with PI controller. 

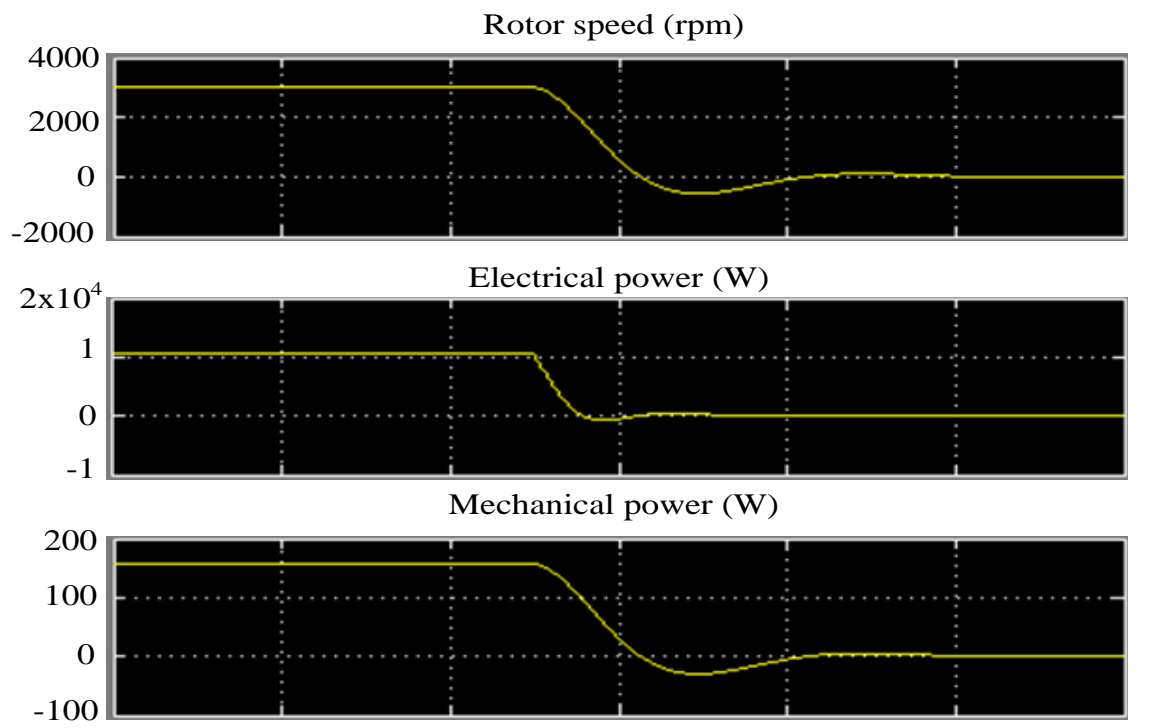

Efficiency $(\%)$
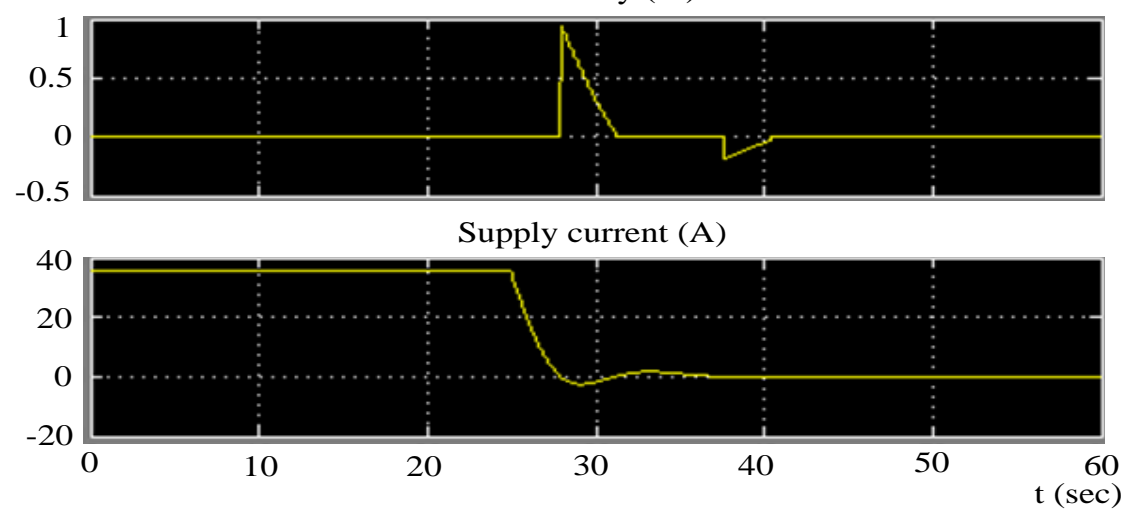

Fig.10:- Simulation results in PI condition.

\section{Case 2- PID condition}

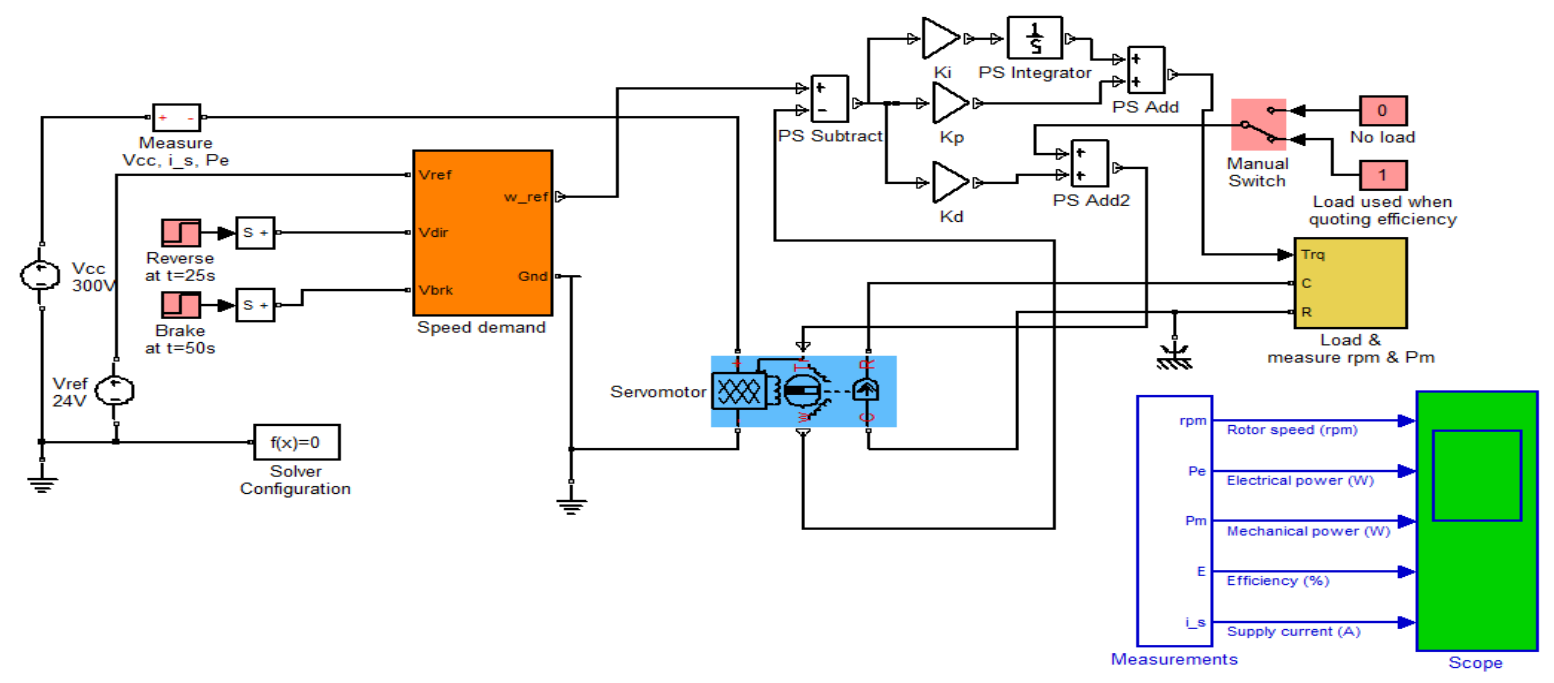

Fig.11:- Simulation model of brushless de servo motor with PID controller. 

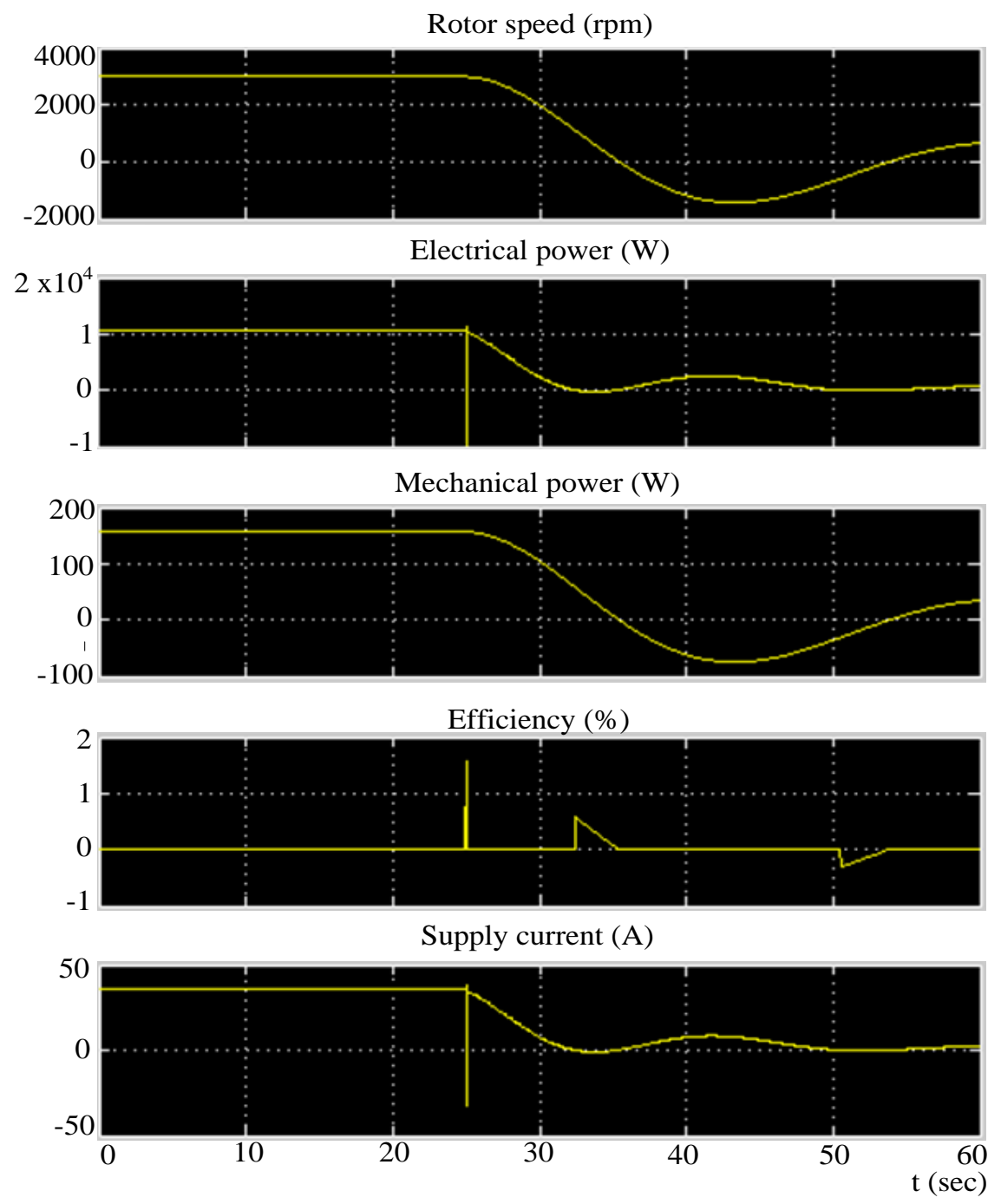

Fig.12:- Simulation results in PID condition.

Regarding the data based on the assumption, the torque is proportional to the current which is equivalent to the driver controlling current. The motor's permissible range of torque and speed is defined by the manufacturer torquespeed envelope, and the output torque is assumed to track the torque reference demand with time constant. Electrical losses assume to be the sum of a torque-independent term plus a term proportional to the square of the torque. In addition, a resistor in series with the supply represents to model transmission losses between power supply and servomotor drive.

Fig. 10 and Fig. 12 show the simulation results in PI and PID conditions. At the simulation results of PI and PID condition, motor speed reaches maximum $3000 \mathrm{rpm}$. The braking time reaches at $25 \mathrm{~s}$. Therefore, electrical power in kilowatts produces $10.5 \mathrm{~kW}$ as motor output. The peak current reaches $38 \mathrm{~A}$ at the same time. In the no load condition, mechanical power has no output.

In the PI case, system response is faster than in the case of using PID as shown in Fig.10 and Fig.12. In the waveform of rotor speed the value of $\mathrm{w}(\Omega)$ can maintain its desired value at 40sec after the stop change in using PI case. However, in the case of using PID, the rotor speed declined in the reverse direction until -2000 rpm. By comparison of the simulation results, system performance by using PI is better than that of using PID controller. 


\section{Acknowledgement:-}

The author would like to express her heartfelt gratitude to Dr. Wunna Swe, Associate Professor, Head of Electrical Power Engineering Department, Yangon Technological University, for his enthusiastic encouragements, helps and instructions. The author also wishes to thank Dr. Zarchi Linn for her helpful suggestions and valuable ideas and all of teachers, Electrical Power Engineering Department, Yangon Technological University. The author expresses her thankful to all persons who concern to support in writing this paper.

\section{Conclusions:-}

As a conclusion, the studying on the Yamathin textile factory was presented. Building the block diagram related with the Flat-Bed Screen Printing Machine used in brushless DC (BLDC) servomotor was configured. . Simulation based on the data of servo motor used in Yamathin textile factory was carried out. And then, the results were comparatively analyzed for servo motor performance by applying the controller of PI and PID. At the simulation results of PI and PID condition, motor speed reaches maximum revolution per minute. The braking time reaches at $25 \mathrm{sec}$ after the processing of printing machine. The electrical power in kilowatts produces $10.5 \mathrm{~kW}$ as motor output. The peak current reaches $38 \mathrm{Amp}$ at the same time in both conditions. In the no load condition, mechanical power has no output. Although rotor speed and mechanical power have the same values in processing of textile printing machine, the three outputs of electrical power, efficiency and supply current have the different condition as the removing on position controlling. According to the results, the outcomes delivered from the PI controller were more preferable than the PID.

\section{References:-}

1. Manafeddin Namazov, DC motor position control using proportional-derivative controllers with different methods, May 26, 2010

2. Ankur Guptal, Aziz Ahmad2, Amit Kumar, Position control of servo motor using sliding mode controller, July 2011

3. Nader Jamali Sufi Amlashi, Design and Implementation of Position Control System for Tracking Applications and Performance Comparison with Conventional PID, March 2012

4. Rajnish Mitter, Krishan Kumar, Vivek Kumar, Simulation of PI logic controller for controlling the position and speed of the DC motor, Issue 1(August 2012)

5. Austin Hughes. Electric Motors and Drives: Fundamentals, Types and Applications. $3^{\text {rd }}$ ed. Elsevier, Ltd., 2006. Page 95.

6. PRESTON MILLER, Anorad Corp. \& MAT LAMMERS, Anorad B.V: Tips for choosing high-accuracy linear positioning systems, June 1994, Power Transmission Design Book, page 69 Wikipedia Network, Internet

7. George W.Younkin, P.E. , Electric Servo Motor Equations and Time Constants

8. EE Times embedded controller website on10/23/2009,http://www.embedded.com/2000/0010/0010feat $3 . h t m$ 